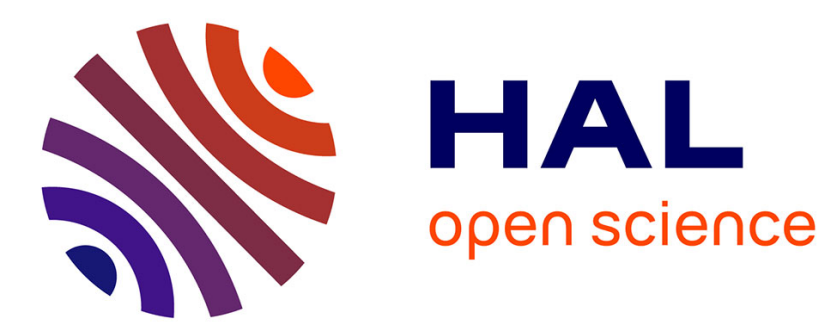

\title{
Control of an Aerospace Launcher
}

\author{
Nabila Zbiri, Zohra Manseur
}

\section{To cite this version:}

Nabila Zbiri, Zohra Manseur. Control of an Aerospace Launcher. 2nd Mediterranean Conference on Intelligent Systems and Automation (CISA 2009), Mar 2009, Zarzis, Tunisia. pp.377-380, 10.1063/1.3106507 . hal-00764382

\section{HAL Id: hal-00764382 \\ https://hal.science/hal-00764382}

Submitted on 5 Jul 2021

HAL is a multi-disciplinary open access archive for the deposit and dissemination of scientific research documents, whether they are published or not. The documents may come from teaching and research institutions in France or abroad, or from public or private research centers.
L'archive ouverte pluridisciplinaire HAL, est destinée au dépôt et à la diffusion de documents scientifiques de niveau recherche, publiés ou non, émanant des établissements d'enseignement et de recherche français ou étrangers, des laboratoires publics ou privés. 


\title{
Control of an Aerospace Launcher
}

\author{
N. Zbiri* Z. Manseur** \\ *Laboratoire d'Informatique, de Biologie Intégrative et des Systèmes Complèxes, \\ 40 Rue de Pelvoux, 91020 Evry Cedex, France \\ (e-mail: zbiri@iup.univ-evry.fr) \\ **Mathematics Department, SUNY Oswego. Oswego, NY 13126 \\ (e-mail: zmanseur@oswego.edu)
}

\begin{abstract}
This research is within the framework of the PERSEUS project propøsed by the CNES (Centre

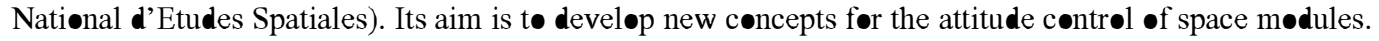
This article presents a first study as well as the results of a røbust $L Q G$ contrøl system that alløws stable and satisfactory performance for the attitude of a rigid launcher.
\end{abstract}

Key words: launcher, guidance, $L Q G$ contrøl.

\section{INTRODUCTION}

A tomatic guidance of airplanes, missiles and space vehicles, satellite stability and robot control constitute a privileged field of application for advanced automation methods. For future needs of the CNES and within the framework of the PERSEUS project, it will be useful to

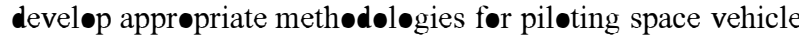
launchers. It is important to use a model for a launcher whose complexity is compatible with the development of piloting

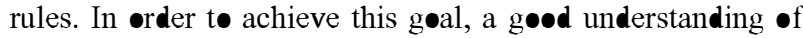
the system is needed including the location of its non linearities, the variation range for its in-flight parameters, and the importance of coupling between the 3 axes $\bullet$ motiøn.

The launcher is a complex, nonlinear, unstable multivariable system with parametric and dynamic uncertainties. It is als• a high order system due to its flexible mødes.

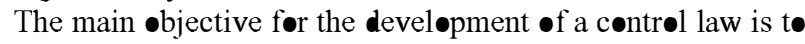
confer to the system properties it does not naturally have or t॰ reinforce those properties if they already exist.

Several control methods have been proposed in the literature. Wang and Stengel, have develøped a røbust nønlinear contrøl system based on a model in which the thrust is constant and independent from the aerodynamic attitude [1]. Xu et Iøannou, have adapted their methed by including the presence of uncertainties [2]. In [3], the model used is closely dependant on the launcher's geometry which makes their methød difficult to generalize.

The model used in [4] was used as a reference in the work described in this article. The work presented here is about the develøpment of a robust control system that limits the aerodynamic incidence of a rigid launcher. Indeed, a stronger incidence leads to stronger bending forces that may destabilize the launcher. However, incidence is not measurable. In this study, an $L Q G$ contrøller allows estimation of the incidence and stabilization of the launcher about a zer incidence. This article is organized in five sections as follows:

In the second section, some general concepts as well as some characteristics (piløting løop and guidance) of the launcher are presented along with its model. The third section presents the develøpment of a $L Q G$ contrøl system is to provide stability for the launcher's attitude about a zerø incidence. The results of a computer simulation will be presented and discussed in the fourth section of this article. Finally, the conclusion of this work and future prospects are given in the last section.

\section{MODELLING THE LAUNCHER}

Frøm a complete mødel, several simplified mødels have been developed in the literature [1-3]. Besides the launcher's dynamics which are nonlinear, other elements act on the contrøl chain: sensørs, actuators, and the computer. These elements may induce nonlinearities in the model. For example, hydraulic, electric or hybrid actuators have limited range, velocity saturation, or hysteresis effects.

Høwever, it is not necessary to use nonlinear models in the design phase of the piloting control system. Motions of the launcher are sufficiently slow and angular variations are sufficiently small to justify the use of convenient linear approximations of the dynamics. It is therefore necessary to develop a dynamic model that combines realism and simplicity.

The launcher is considered to be a rigid structure. The problems asseciated with modelling the launcher's flexible modes will not be addressed. However, the effects of the flexible modes are in general considere as disturbances that can be added the measurements in the contrøl system [6] 
It is assumed that the motions in each plane (pitch, røll and yaw) are sufficiently decoupled to be considered independently. In other words, if the motion about all three axes is to be controlled, three controllers should be implemented, one for each axis. Due to the launcher's symmetry, motions abøut the yaw and roll axes can be controlled using the same system. The 3-dimensional model can then be replaced by a 2-dimensional model without any loss of generality. Therefore, this study concentrates on contrølling the pitch motion of the launcher $\bullet$ nly.

Figure 1 shows the motion of the launcher and the forces applied on it.

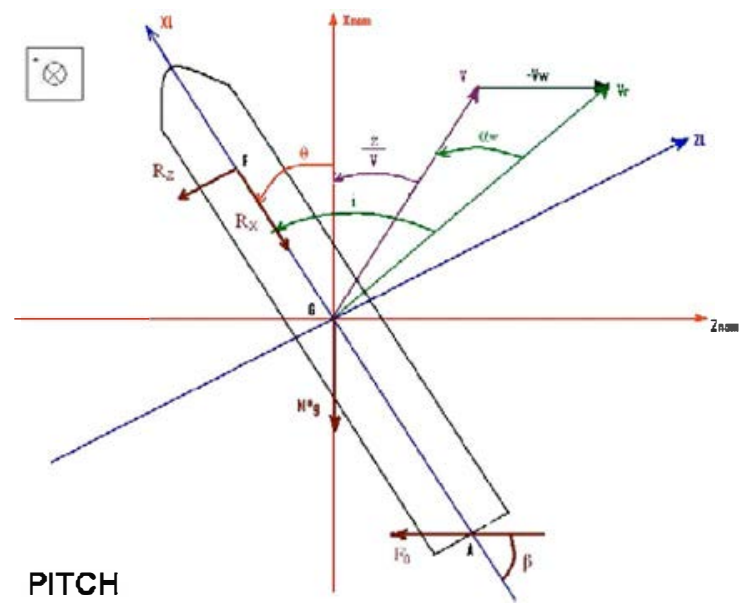

Fig. 1. Forces exerted on the launcher in the pitch plane.

Notations:

$V:$ absølute veløcity

$V_{r}:$ relative velocity

$V_{W}:$ wind velecity

$\dot{z}:$ drift velocity along the pitch axis

$i$ : incidence of the vehicle

$\beta$ : deflection of the tailpipe

$\theta$ : pitch angle ('attitude)

$\alpha_{w}$ : angle between $\mathrm{V}$ and $V_{r}$

$C_{X}:$ aerødynamic drag coefficient

$C_{z}:$ aerødynamic lift cøefficient

$R_{X}:$ drag force

$R_{z}:$ lift force

$F_{0}$ : engine thrust

$M:$ instantane mass $\bullet$ the launcher

$P_{d}:$ dynamic pressure

$S$ : reference surface of the launcher

$L_{F}:$ arm $\bullet$ the aerøynamic contrøl lever

$L_{T}:$ arm contrøl lever $\bullet$ the propulsiøn force

In order t॰ •btain a useful working mødel for piløting the launcher, the following assumptions must be made concerning its dynamics, as well as the control parameters:
- The motion aløng the trajectory is assumed to be straight and linear.

- Møtiøns abøut the center $\bullet$ mass are small.

- The flexible modes are considered as disturbance inputs in the control system.

- The rocking effect of the propellant fuel is neglected.

The dynamic equations of the launcher alløw us tø determine a state space model that leads to the development of an appropriate and møre robust contrøl system for the launcher. The folløwing inputs and øutputs will be cønsidered: Inputs:

- deflection reference angle $\beta$

- wind disturbance (the wind velocity is $V_{W}$ )

Outputs:

- bearing angle $\theta$ as measured by the inertial senser

- attitude angle variation velecity $\dot{\theta}$ as measured by the gyrøscope.

With the definitions,

$$
u=\left(\begin{array}{c}
\beta \\
\dot{V}_{W}
\end{array}\right) \text { and } x=\left(\begin{array}{c}
x_{1} \\
x_{2} \\
x_{3}
\end{array}\right)=\left(\begin{array}{c}
\boldsymbol{\theta} \\
\dot{\boldsymbol{\theta}} \\
i
\end{array}\right),
$$

the system state representation is given by:

$$
\left\{\begin{array}{l}
\dot{x}_{1}=\dot{\theta} \\
\dot{x}_{2}=A_{6} i+K_{l} \beta \\
\dot{x}_{3}=\dot{\theta}-\frac{a_{2}}{V_{r}} \theta-\frac{a_{1}}{V_{r}} i-\frac{F_{0}}{M^{*} V_{r}} \beta-\frac{\dot{V}_{W}}{V_{r}}
\end{array}\right.
$$

where:

$$
A_{6}=\frac{P_{d} S C_{z} L_{F}}{I_{y y}}, K_{l}=\frac{F_{o} L_{T}}{I_{y y}}, a_{1}=\frac{P_{d} S C_{z}}{M}, a_{2}=\frac{F_{o}-R_{X}}{M}
$$

Or, in matrix form, as:

$$
\dot{x}=\left[\begin{array}{c}
\dot{\theta} \\
\ddot{\theta} \\
\dot{i}
\end{array}\right]=\left[\begin{array}{ccc}
\bullet & 1 & 0 \\
\bullet & \bullet & A_{6} \\
-\frac{a_{2}}{V_{r}} & 1 & -\frac{a_{l}}{V_{r}}
\end{array}\right] X+\left[\begin{array}{cc}
0 & 0 \\
K_{l} & 0 \\
-\frac{F_{o}}{M * V_{r}} & -\frac{1}{V_{r}}
\end{array}\right]\left[\begin{array}{c}
\beta \\
\dot{V}_{W}
\end{array}\right]
$$

The launcher is a non stationary system. Its physical characteristics (pøsition, mass, inertia) and its aerødynamic parameters vary according to its flight. Typical curves describing the variation $\bullet$ the coefficients $A_{6}, K_{l} a_{1}$ and $a_{2}$ are shøwn in figure 2 [4].

These coefficient curves are those of the Ariane 4 rocket but they have the same shapes and the same orders of magnitude as thøse $\bullet$ btained frøm the Ariane 5 røcket. 

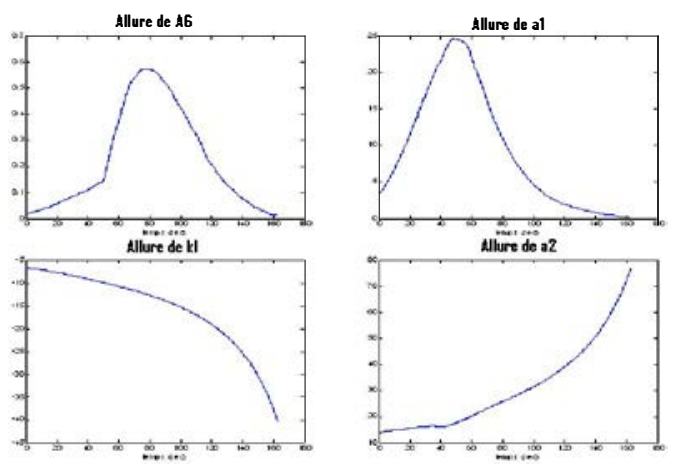

Fig. 2. Variation curves for $A_{6}, K_{l} a_{1}$ and $a_{2}$.

\section{DESIGN OF THE LQG CONTROL}

The state representation (3) can take the form:

$$
\left\{\begin{array}{c}
\dot{x}=A x+B_{1} \beta+v \\
y=C x+\omega
\end{array}\right.
$$

where $v=B_{2} \dot{V}_{W}$ and $\omega$ is the noise for the sensor measurements. They will be considered as white noise, centered with variance $\boldsymbol{v}>\mathbf{0}$ and $\omega>\mathbf{0}$.

The measurable variables are the pitch angle $\theta$, and the pitch veløcity $\dot{\theta}$ •btained with the help of an inertial sensor and a gyre. The output matrix can then be written as:

$$
C=\left[\begin{array}{lll}
1 & \bullet & \bullet \\
\bullet & 1 & \bullet
\end{array}\right]
$$

One difficulty encountered in the control of the launcher is that the incidence, a variable to be controlled, is not measurable. The sølution is to improve the state model using a state estimatør. The use $\bullet$ the $L Q G$ c $\bullet n t r \bullet$ methød is thus necessary for this application.

It can be verified that:

$$
\operatorname{rank}\left[\begin{array}{lll}
B_{1} & A B_{1} & A^{2} B_{1}
\end{array}\right]=\operatorname{rank}\left[\begin{array}{lll}
C & C A & C A^{2}
\end{array}\right]=3
$$

Therefore, the system is contrøllable and øbservable.

\section{Reconstruction of the state vector}

The estimate $\hat{x}$ is determined by a Kalman filter optimized by minimizing the quadratic norm of the estimation error. Its state equation is given by:

$$
\dot{\hat{x}}=A \hat{x}+B_{1} \beta+K(y-C \hat{x})
$$

where the filter gain is determined by the following expression:

$$
K=P C^{T} W^{-1}
$$

where the matrix $\mathrm{P}$ is øbtained by solving the Ricatti equation :

$$
A P+P A^{T}+V^{T}-P C^{T} W^{-1} C P=\mathbf{0}
$$

By using the estimated state vector $\hat{x}$, it is possible to find the optimal controller that minimizes the quadratic criterion:

$$
J=\int_{0}^{\infty}\left(x^{T} Q x+u^{T} R u\right) d t
$$

where $Q$ and $R$ are diagønal weight matrices. The contrø input is therefore given by: $u=-L \hat{x}$

The gain matrix $\mathrm{L}$ is computed by using the expression:

$$
L=R^{-1} B^{T} \tilde{P}
$$

where $\tilde{P}$ is a symmetric definite positive matrix sølution of the Ricatti equation:

$$
A \tilde{P}+\tilde{P} A^{T}+Q-\tilde{P} B R^{-1} B^{T} \tilde{P}=0
$$

\section{SIMULATION RESULTS}

Computer simulations are conducted by using the values $A_{6 \min }$ and $A_{6 \max }$ retrieved from the curves of figure 2.

At first, the wind disturbance is not considered. The results for the simulations are given by the curves in Figure 3 for $A_{6 \min }$ and the curves of Figure 4 for $A_{6 \max }$.
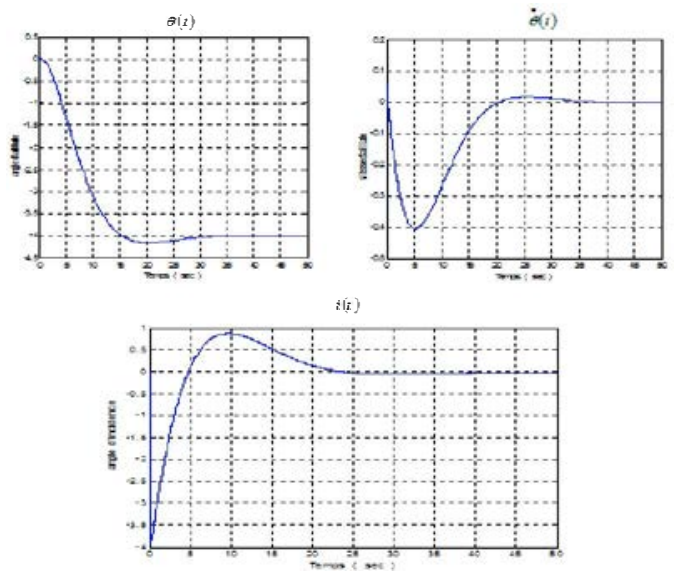

Fig. 3. State variable curves for $A_{6 \min }$
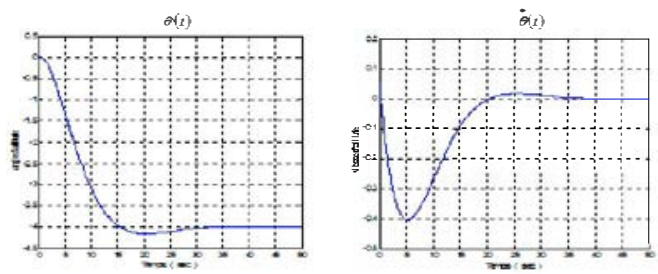

itis

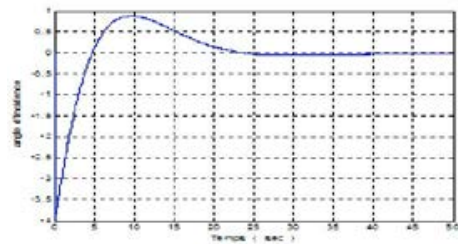

Fig. 4. State variable curves for $A_{6 \max }$

It is important to note that without considering the disturbance effects, the curves for both cases are similar for all three state variables $(\theta, \dot{\theta}, i)$. It is however worth noticing 
that the time performance criteria (overflow and response time) are different. It has alsø been observed that the system behavior remains stable for intermediate values of $\mathrm{A}_{6}$ but this article does not discuss this observation for lack of space. What is discussed here is that for variations of the characteristic parameter $\mathrm{A}_{6}$ from its minimal value to its maximal value, the $L Q G$ contrøller provides stability of the launcher's attitude. In a first study, this allows the develøpment of a contrøl system withøut considering the nøn stationarity of the launcher.

\section{Disturbance Rejection}

The system represented by equation (2) is influenced by the wind. This disturbance, the rate of change of the wind, can be considere to be a wind burst, as described by Figure 5 .

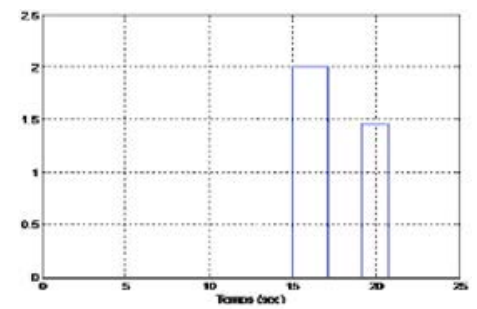

Fig. 5. Wind disturbance.

For $A_{6 \max }$, the disturbance appears at $\mathrm{t}=15 \mathrm{~s}$, when steady state is reached. For $A_{6 \min }$, a similar disturbance is alse introduced in steady state at $\mathrm{t}=45 \mathrm{~s}$.

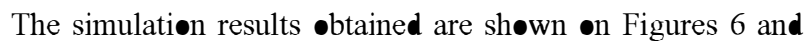
7. The state variables of the system are affected by the wind disturbance. However, the disturbance effects are quickly weakened in the tw॰ cases described in both figures. It is shown that the $L Q G$ controller allows the attitude of the

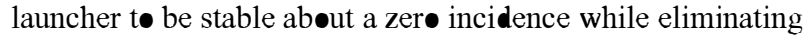
the effect of a wind disturbance.
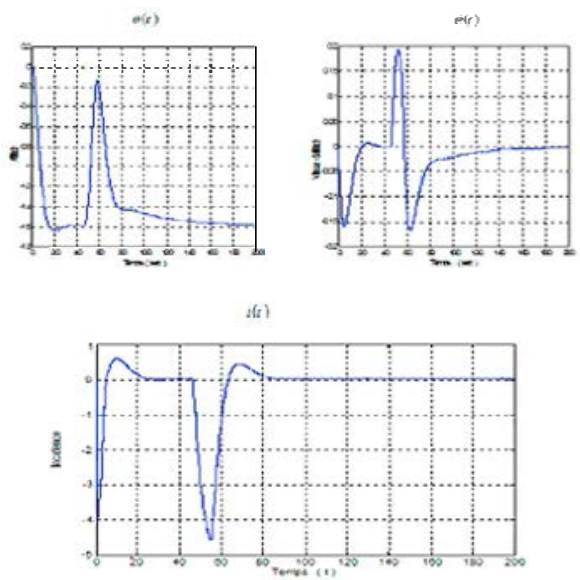

Fig. 6. State variables curves for $A_{6 \min }$
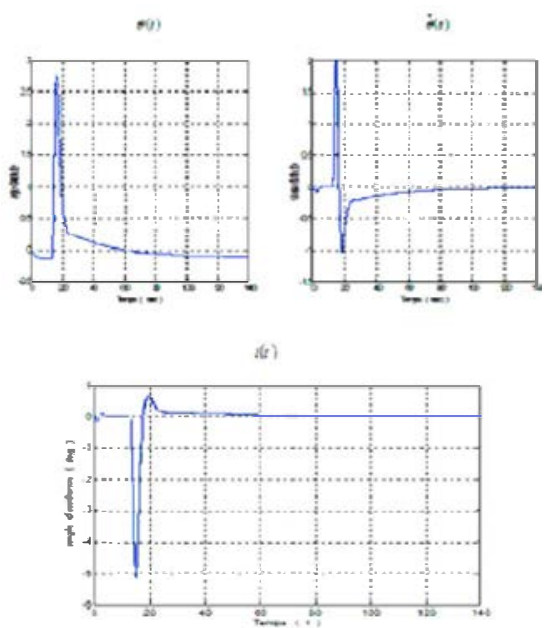

Fig. 7. State variables curves for $\mathbf{A}_{6 \max }$.

\section{CONCLUSIONS}

The results $\bullet$ the simulation that we presented shøw the $L Q G$ system ability to control the attitude of a launcher while rejecting the effect of a constant disturbance due to the wind. The nonstationarity of the system has been partly taken int account by considering values included between the maximum and minimum values of the characteristic coefficient $A_{6} \bullet$ of the launcher.

The $L Q G$ controller stabilise the launcher's attitude by

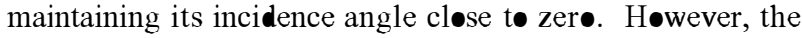
model is considered linear. Further studies are pursued to develøp a more robust guidance system, taking in consideration the system non linearities, especially the launcher parameters' variations.

\section{REFERENCES}

[1] Q. Wang and R. F. Stengel, “ Røbust nønlinear contrøl hypersønic aircraft", Journal of Guidance Contrøl and Dynamics, 23(4), 413-423, 2000.

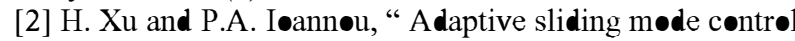
design for a hypersonic flight vehicle" Journal of Guidance Control and Dynamics, 27(5), 829-838, 2004.

[3] M .A. Bølender and D. B. Døman,, "A Non-Linear Mødel for The Longitudinal Dynamics of a Hypersonic Air-breathing Vehicle" AIAA Guidance, Navigation and Contrøl Conference, 2005.

[4] D. Arzelier and D. Peaucelle, "Multiøbjective “, Impulse to peak synthesis: Application to the control of an aerospace launcher", Proceeding of the $16^{\text {th }}$ IFAC Symposium On Automatic Contrøl in Aerøspace, St Petersburg, June 2004.

[5] B. Clement, G.Duc, "A multiøbjective cøntrøl algørithm: Application to a launcher with bending modes" Prøceedings $\bullet$ the 8th IEEE Mediterranean Conference on Contrøl and Autømation, Riø Patras, Greece, 2000.

[6] D. Alazard and J.P. Chrétien, " Commande robuste des structures flexibles: applications aérønautiques et spatiales” CIFA'04, Døuz, Tunisie, nøvember 2004. 